\title{
Article \\ Korean Panax Ginseng Reduces Orthodontic Tooth Movement in Rats
}

\author{
Reza Talebian $^{1,2,3} \mathbf{D}^{\mathbb{D}}$, Vahid Mollabashi ${ }^{3} \mathbb{D}$, Arezoo Motaghedifard ${ }^{4} \mathbb{D}$ and Reinhard Gruber ${ }^{1,5, *}$ \\ 1 Department of Oral Biology, University Clinic of Dentistry, Medical University of Vienna, 1090 Vienna, \\ Austria; drrezatalebian@outlook.com \\ 2 Experimental Medicine Research Center, School of Medicine, Tehran University of Medical Sciences, \\ Tehran 1416753955, Iran \\ 3 Department of Orthodontics, School of Dentistry, Hamadan University of Medical Sciences, \\ Hamadan 65175-4171, Iran; mollabashi@umsha.ac.ir \\ 4 Dental Research Center, Zahedan University of Medical Sciences, Zahedan 9816743463, Iran; \\ arezoomotaghedi@gmail.com \\ 5 Department of Periodontology, School of Dental Medicine, University of Bern, 3010 Bern, Switzerland \\ * Correspondence: reinhard.gruber@meduniwien.ac.at; Tel.: +43-699-107-18-472
}

Citation: Talebian, R.; Mollabashi, V.; Motaghedifard, A.; Gruber, R. Korean Panax Ginseng Reduces Orthodontic Tooth Movement in Rats. Appl. Sci. 2021, 11, 8856. https://doi.org/ 10.3390/app11198856

Academic Editor: Joseph Nissan

Received: 28 July 2021

Accepted: 15 September 2021

Published: 23 September 2021

Publisher's Note: MDPI stays neutral with regard to jurisdictional claims in published maps and institutional affiliations.

Copyright: (c) 2021 by the authors. Licensee MDPI, Basel, Switzerland. This article is an open access article distributed under the terms and conditions of the Creative Commons Attribution (CC BY) license (https:// creativecommons.org/licenses/by/ $4.0 /)$.

\begin{abstract}
Ginseng, a herbal plant, is rich in pharmacologically active ginsenosides capable of promoting bone regeneration and of reducing inflammatory osteolysis. Ginseng was therefore proposed to reduce the catabolic changes during periodontitis. Here, we tested the capability of ginseng to modulate orthodontic tooth movement (OTM). To this aim, 55 male Sprague Dawley rats were randomly distributed into five groups: (I) a normal group without any interventions; (II) an untreated OTM serving as a control; and (III, IV, and V) treated OTMs receiving daily oral administrations of 75, 150, and $300 \mathrm{mg} / \mathrm{kg}$ of a standardized extract from the roots of Korean Panax ginseng G115 for three weeks, respectively. The molar tooth was moved towards the incisor during three weeks followed by measurements of the distance between the first and the second molars. Moreover, the impact of OTM and ginseng extracts on body weight was determined. Our data showed that, compared with the OTM control, 150 and $300 \mathrm{mg} / \mathrm{kg}$ of G115 ginseng extract significantly decreased the OTM from $0.87 \mathrm{~mm}(\min 0.69 ; \max 0.96)$ to $0.53(\min 0.42, \max 0.62 ; p=0.002)$ and $0.36(\min 0.27$, $\max 0.43 ; p<0.0001$ ), respectively. Moreover, 150 and $300 \mathrm{mg} / \mathrm{kg}$ of G115 significantly lowered the body weights of the rats when compared with the respective controls $(p=0.002$ and $p<0.0001$, respectively). These findings suggest that extracts from Panax ginseng are capable of reducing orthodontic tooth movement in rats and is associated with a decrease in body weight.
\end{abstract}

Keywords: ginseng; G115; orthodontic tooth movement; bone remodeling; rats; body weight

\section{Introduction}

Orthodontic tooth movement (OTM) is a consequence of applied forces that translate into a biological response with the hallmarks of osteoclastic bone resorption on the pressure side and concomitant osteoblastic bone formation on the tension site [1,2]. Considering the complexity of the local signals that translate into the cellular action required to initiate local bone resorption and formation, research attempts to find strategies to modulate OTM remain challenging. These research attempts are particularly important in better understanding the biology of OTM. Overall, there is great support for the hypothesis that OTM is a consequence of the local inflammation driving osteoclastogenic bone resorption, at least to some extent $[3,4]$. Support for this hypothesis comes from observations that the inhibition of inflammation, for example, through blocking cyclooxygenase-2 activity, greatly reduces OTM in rodent models [5,6]. Aspirin also reduces the relapse rate following OTM in rats [7]. In support of this concept, inflammatory cytokines such as TNF $\alpha$ and the positive ratio of the pro-inflammatory M1 to the pro-resolving M2 macrophages increased OTM [8,9]. OTM studies using transgenic animal models provide further insight into the 
cellular events and the molecular regulation of OTM, including inflammation [10]. In general, a reduction in inflammation reduces OTM.

A reduction in inflammation and thus a potential reduction in OTM is not exclusively achieved by pharmacological compounds. Natural resources such as plant derivatives are a rich source of bioactive molecules with great pharmacological importance. In traditional Asian medicine, the roots of Panax ginseng have received much attention over the centuries [11,12]. Today, we know that ginseng has a large number of bioactive molecules commonly known as ginsenosides [13] that may be responsible for the therapeutic effects but not limited to weight loss [14] and combating cardiovascular diseases [15], diabetes mellitus [16], neurological diseases, and inflammatory bowel disease [17]. Ginseng exerts its beneficial effects by reducing inflammation [18] through the activation of nuclear factor erythroid 2-related factor 2 (Nrf2)-heme oxygenase 1 (HO1) signaling [19,20]. In this context, activating Nrf2-HO1 signaling attenuated OTM in mice [21]. In vitro, Nrf2 and HO1 activation inhibited osteoclastogenesis [22,23].

Standardized extracts of Korean Panax ginseng (G115) were introduced already in the 1980s [24] to overcome the high variability in their composition and to improve the overall quality of ginseng products on the market [25]. In an experimental setting, it is important to use pure and standardized ginseng extracts such as G115 to allow for the research to be reproducible and to guarantee the effectiveness and safe use of the extract. G115 is a good example of a herbal drug prepared with safety and efficacy in mind power when producing the herbal medicinal products. Clinical trials and 50 years of presence on the market support the safety profile of G115 [25]. Furthermore, G115 was widely used in rat preclinical research $[24,26,27]$ and is therefore ideal for preclinical testing in an OTM model. Taking advantage of this model, we investigated the impact of Korean Panax ginseng on OTM.

\section{Materials and Methods}

\subsection{Animals}

Fifty-five male Sprague Dawley rats with an average age of $13 \pm 1$ weeks and average weight of $275 \pm 25 \mathrm{~g}$ obtained from the Pasteur Institute of Iran were used in this study. In adult rats, OTM seems to be efficient [28] and not highly affected by the bone turnover process occurring during the growth cycle [29]. The animals were kept in plastic cages with a standard $12 \mathrm{~h}$ light-dark cycle. A diet of soft laboratory pellets was used for feeding to minimize animal discomfort and the possibility of intraoral appliance displacement. Animals had free access to water and pellets. The study was performed according to the Guide for the Care and Use of Laboratory Animals published by the US National Institutes of Health (NIH Publication No. 85-23. revised 1985). The rats were randomly divided into five groups ( $n=11$ in each group): (I) a normal group without any interventions, neither OTM appliances nor treatments; (II) a control group in which OTM appliances were fixed intraorally and daily sterilized standard $0.9 \%$ saline were received through gastric gavages by oral intubation; and (III, IV, V) G-75, G-150, and G-300 groups in which, in addition to the fixed intraoral OTM appliances, rats were treated with 75,150 , and $300 \mathrm{mg} / \mathrm{kg}$ of G115 dissolved in sterilized standard $0.9 \%$ saline daily through gastric gavages by oral intubation, respectively. The animals were weighted at the beginning and at the end of the study.

\subsection{Orthodontic Treatment}

Each rat was anesthetized with an intraperitoneal injection of Ketamine hydrochloride at $100 \mathrm{mg} / \mathrm{kg}$ body weight (Pharmacia \& Upjohn. Erlangen, Germany) and Xylazine $\mathrm{HCl}$ at $5 \mathrm{mg} / \mathrm{kg}$ body weight (Rompoun, Bayer, Leverkusen, Germany). The setting of the orthodontic appliances was similar to what was presented by King and Fischischweiger [30]. In brief, an orthodontic force was applied using a $0.006 \times 0.022$ Nitinol closed-coil spring with a $5 \mathrm{~mm}$ length (3M/Unitek Hi-T II. Monrovia, CA, USA) running between the right, upper, first molar and incisors. The spring was fixed in place via 0.010 " steel ligature wires 
(Dentaurum, Ispringen, Germany) surrounding the molar tooth and incisor. A cervical groove was designed on the incisor area, and the ligature wire was inserted. A self-cured composite resin (Bisfil ${ }^{\mathrm{TM}}$ 2B, Bisco, Schaumburg, IL, USA) was used to secure the wire on both incisors. According to Heller and Nanda's method [31], the spring was activated to provide $60 \mathrm{~g}$ of force. Treatment continued over three weeks, while the appliances regularly exerted force (Figure $1 \mathrm{~A}-\mathrm{C}$ ). The animals were sacrificed by narcosis and immediately decapitated.

\subsection{OTM Measurement}

Using a calibrated Feeler Gauge (Mitutoyo Co. Kawasaki-Shi, Japan) with $0.01 \mathrm{~mm}$ increments, OTM was measured directly in the mouth to reveal the distance between reference points of the disto-occlusal and mesio-occlusal tips of the first and second maxillary molars, respectively (Figure 1D,E). This manual method has been widely used also in previous preclinical models of rat OTM [6,32-35]. To prevent any potential relapse of tooth movement before removing the appliances, a silicone impression (Zermack, Mahl, Germany) was taken and ultra-strength dental stone (Velmix, Gildand, Germany) was poured into a mold to create a model. Re-measurement was performed by using the same Feeler Gauge on the plaster replica, which confirmed the first direct measurement. The same operator performed all of the measurements. However, the principle of the method of OTM measurement was based on manual use of a Feeler Gauge. To more clearly show the resultant space due to orthodontic movement of the first molar, as a sample, a lateral cephalometric radiograph from a supine rat of the OTM group was prepared at the first and at the end of the study using a setting of $60 \mathrm{kVp}, 8 \mathrm{~mA}$ in $0.4 \mathrm{~s}$ provided by a Pleomorphism analog digital radiography unit (Siemens Healthcare $\mathrm{GmbH}$, Erlangen, Germany) based on the method previously described by our Iranian colleagues (Figure 1F,G).
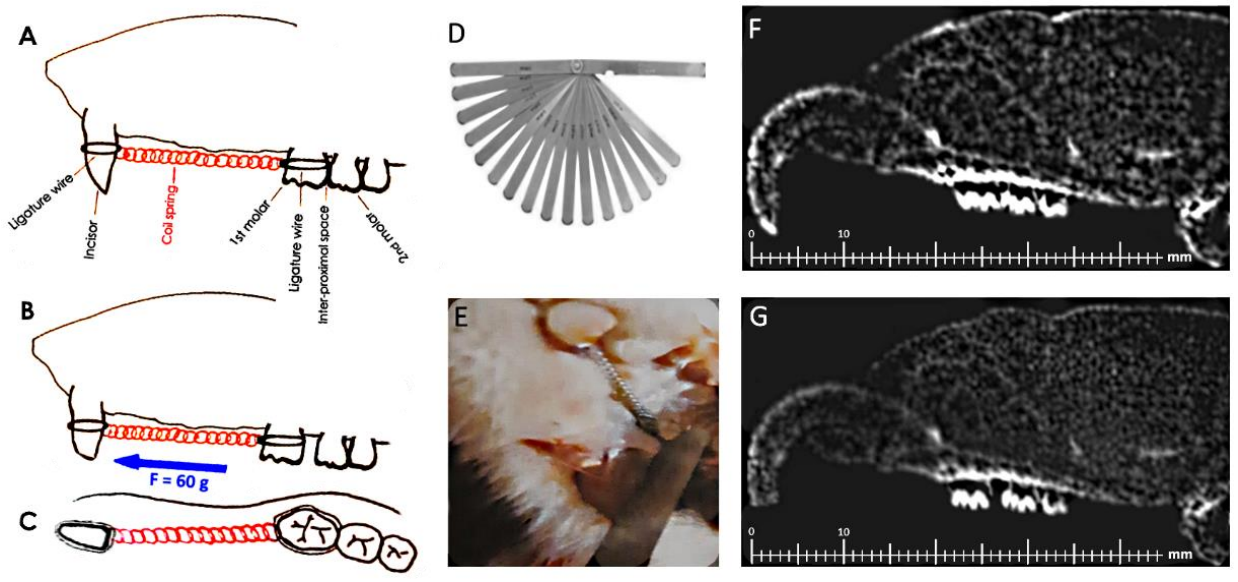

Figure 1. Applied forces through OTM appliances resulted in an inter-proximal space. (A) Before applying the force, the inter-proximal space between the first and second molars was zero. (B) A distance was created between the first and second molars due to the applied force. The first molar was pulled towards the incisor teeth by an activated coil spring providing $60 \mathrm{~g}$ of force. (C) OTM appliance setting from an occlusal view. (D) A Feeler Gauge used for manual measurement of a gap (E) Use of a Feeler Gauge for the measurement of a distance between the molar teeth on a rat jaw. $(\mathbf{F}, \mathbf{G})$ Radiographs showing rat maxillary jaws without and with the first molar moved, respectively.

\subsection{Statistical Analysis}

Based on previous research in the same field [35-37], considering a type I $\alpha$-error of 0.05 , and to reach a power of $80 \%$, the fewest number of animals per group was eleven. The nonparametric Kruskal-Wallis test with post hoc Dunn's test for multiple comparisons of the data was applied to analyze the data. Statistically, a $p$-value less than 0.05 was considered significant. The data are shown as dot blots and as a median. 


\section{Results}

\subsection{Orthodontic Tooth Movement}

Compared with the contralateral first molar serving as a control, the OTM of untreated control rats had a median of $0.87 \mathrm{~mm}(\min 0.69$; $\max 0.96)$. As shown in Figure 2, G115 at $75 \mathrm{mg} / \mathrm{kg}$ failed to significantly affect OTM, which was $0.75 \mathrm{~mm}$ (min 0.53; max 0.86, $p=0.60$ ). However, at a higher concentration of the ginseng extract, namely $150 \mathrm{mg} / \mathrm{kg}$, OTM was significantly reduced to $0.53 \mathrm{~mm}(\min 0.42 ; \max 0.62 ; p=0.002)$. Even more robust was the effect of $300 \mathrm{mg} / \mathrm{kg}$ of the ginseng extract, causing a significant decrease in OTM to $0.36 \mathrm{~mm}$ ( $\min 0.27 ; \max 0.43 ; p<0.0001$ ). These findings suggest that $\mathrm{G} 115$ can reduce the OTM in the rat model.

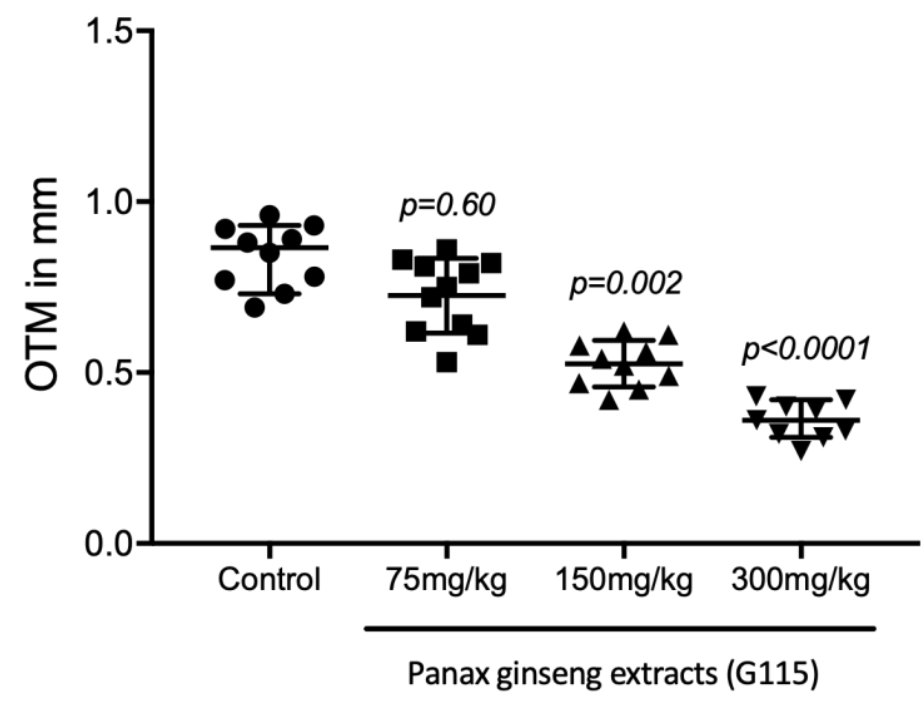

Figure 2. Orthodontic tooth movement (OTM) changes by Panax ginseng extracts.

The orthodontic force was applied to move the right, upper, first molar towards the upper incisors. Three weeks following appliance insertion, OTM was measured directly in the mouth to reveal the resultant distance between the first and second right maxillary molars and was confirmed by re-measurements on the plaster replica. The statistics were based on a nonparametric Kruskal-Wallis test with post hoc Dunn's test for multiple comparisons of data. Please note that 150 and $300 \mathrm{mg} / \mathrm{kg}$ of G115 significantly reduced OTM compared with the untreated control group with OTM.

\subsection{Body Weight}

Considering the known effects of ginseng extracts on weight loss [14] and to obtain an independent parameter that measures the activity of G115, we determined the body weight of the animals. As it is shown in Figure 3, after three weeks, OTM alone had no significant impact on the body weight of the rats, which had a median of $301 \mathrm{~g}$ (min 265; max 320) when compared with the body weight of animals without OTM (normal rats), which was $302 \mathrm{~g}$ (min 263; $\max 321$ ). No significant impact of the $75 \mathrm{mg} / \mathrm{kg}$ ginseng extract on the body weight, which was $274 \mathrm{~g}(\min 242 ; \max 305, p=0.28)$, was found. However, already $150 \mathrm{mg} / \mathrm{kg}$ of G115 significantly lowered the body weight to $251 \mathrm{~g}$ (min 220; $\max 285$, $p=0.002$ ), and $300 \mathrm{mg} / \mathrm{kg}$ of the ginseng extract further reduced the body weight to a median of $241 \mathrm{~g}(\min 219 ; \max 260, p<0.0001)$. These data confirm that ginseng extracts can lower the body weight of rats, providing strong support for the biological activity and the systemic effect of the standardized ginseng extract. 


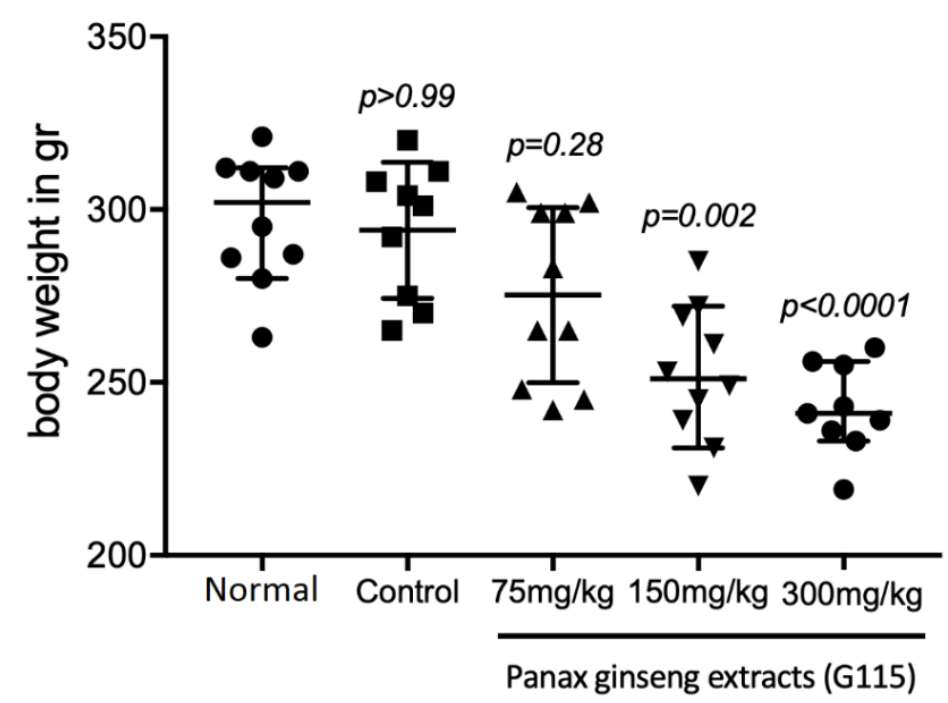

Figure 3. Body weight changes by Panax ginseng extracts.

Body weight was measured following a three-week treatment period. Statistics were based on a nonparametric Kruskal-Wallis test with post hoc Dunn's test for multiple comparisons of data. While untreated rats with OTM (the control group) did not experience a statistically meaningful weight change compared with the normal rats, obviously, 150 and $300 \mathrm{mg} / \mathrm{kg}$ of G115 significantly lowered the body weight compared with the untreated non-OTM normal group.

\section{Discussion}

Orthodontic tooth movement takes advantage of the inflammatory mechanisms that start once a tooth is moved towards its surrounding alveolar bone [1,2]. Inflammatory mechanisms culminate in the formation and activation of the bone-resorbing osteoclasts, making space for the tooth to move $[1,2]$. This is what happens on the pressure side. On the tension side, bone-forming osteoblasts are initiated to allow the bony support to be regained and to hold the tooth in its new position. Thus, if force-induced inflammation is of major importance for OTM [3,4], then the causes of changes in inflammation may also affect OTM. This view is perhaps simplified but works as a working hypothesis. On a molecular level, we learned that OTM is diminished by Nrf2-HO1 signaling [13] and that ginseng extracts can increase Nrf2-HO1 signaling [11,12]. Thus, the suggestion that ginseng extracts possibly attenuate OTM is well-supported.

In support of this assumtion, our data show that, at higher concentrations of the ginseng extract, namely 150 and $300 \mathrm{mg}$ of G115 per kg of body weight, OTM was significantly reduced compared with the untreated normal group. In this view, we have to consider anti-inflammatory compounds to decrease OTM. Some examples are that, through the inhibition of prostaglandin production, OTM is reduced in rats [5-7]. Consistently, ginseng extract and its ginsenosides decrease prostaglandin production in macrophages [38]. Still, (I) how the ginsenosides and maybe other compounds released by ginseng reaches periodontal space, (II) if the effects of ginseng extracts are indirect via suppression of the inflammatory signals required for osteoclastogenesis and bone resorption, and (III) if ginseng compounds may even directly decrease the resorptive capacity of the mature osteoclasts remain unclear. We propose that a reduction in OTM is caused by the systemic anti-inflammatory activity of the bioactive compounds of ginseng extracts.

The weight loss in rats treated with 150 and $300 \mathrm{mg}$ of G115 per kg body weight was originally not considered an endpoint but was significant. Our findings are less surprising if we appreciate that ginseng extracts reduced obesity-related lipid metabolism in mice fed a long-term high-fat diet [39]. Additionally, in high-fat-diet rats, weight reduction, especially fat mass reduction, was observed in the ginseng extract-treated group [40]. Weight loss 
can be linked to changes in lipid metabolism by lowering the levels of cholesterol, lowdensity lipoprotein-cholesterol, and serum triglycerides [39], which may even affect the formation of bioactive lipid mediators that control the resolution of inflammation such as resolvins [41]. Hence, our observation, however independent of OTM measurements, supports observations of the effect of ginseng extracts on reducing body weight. Care should be taken when interpreting the preclinical findings as an adult person has to reach a daily intake of around 10-30 g of the G115 ginseng extract to lose weight, which is comparatively much. We have to admit that a rodent model does not necessarily represent a clinical situation and that dosing cannot be directly translated into patients.

One other limitation of our descriptive study is that the underlying mechanisms by which G115 ginseng extracts reduce OTM and lower body weight remain unclear. It would be interesting to confirm the activation of the Nrf2-HO1 axis by ginseng in our model $[19,20]$ and to show that this axis is responsible for the suppression of osteoclastogenesis [22,23], based on the observation that Nrf2-HO1 signaling attenuated OTM in mice [21]. Future studies should therefore use Nrf2 or HO1 knockout mice where, at least in theory, G115 ginseng extracts should not reduce OTM. Another limitation is that we did not include a control group where an agonist of Nrf2-HO1 signaling pushes OTM. It would further be interesting to link the decreased OTM observed with $\mathrm{LiCl}$, an agonist of the canonical Wnt signaling and the hypothalamus-pituitary-adrenal axis, and L-NAME, an inhibitor of nitric oxide synthases activity [35], to the Nrf2-HO1 axis and to our present findings observed with G115 ginseng extracts. In general, there is a great demand to understand how we can modulate and particularly stimulate OTM by means of herbal medicine. Thus, our finding that G115 ginseng extracts reduce OTM is exciting and may lead to a new hypothesis on how to support OTM.

Radiography and scanning electron microscopy (SEM) of the teeth root surfaces could provide clearer and stronger evidence regarding the force-induced root reportion as a result of G115 intake co-administrated with the OTM treatments; however, this study lacking these advantages. Another limitation could be the use of the Feeler Gauge. Although relatively old, it is considered a standard method for measurement of the space between the adjacent teeth [42]. Different experiments and a similar method we applied to measure the gap resulting from orthodontic tooth movements have already benefited from using a Feeler Gauge [6,32-35]; however, based on the available equipment and techniques, micro-CT and newer techniques may provide more accurate and reliable results.

Among the limitations, is also that an evaluation of the possible adverse effects in regular consumption of ginseng seems to be difficult due to inadequate knowledge on not only the types but also on the content of ginseng; however, Ginseng Abuse Syndrome has been reported in an overdose case exceeding $15 \mathrm{~g}$ of daily intake of ginseng [43]. For human use, up to three months of daily intake of 1 to $2 \mathrm{~g}$ of dried ginseng root powder as a crude preparation has been reported to be safe, and accordingly, no any contraindication for the intake of ginseng has been yet reported by the WHO. In traditional Korean medicine, $2.7 \mathrm{~g}$ to $4.5 \mathrm{~g}$ of ginseng is the most frequent daily dose, while $3 \mathrm{~g}$ is the most frequent daily dose in research from the current decade regarding ginseng [44]. It is hard to conclude what is the effective dose for humans based on rodent models; hence, the data have to be interpreted accordingly.

Taken together, we show here that the standardized Panax ginseng extract can significantly reduce OTM in rats. The meaningful loss in weight of the animals was directly proportional to the concentration of the administered Panax ginseng. In conclusion, our short study suggests that Panax ginseng exerts significant dose-based reduction effects on OTM and body weight in rats.

Author Contributions: R.G. and R.T. contributed to the conception and design of the study; to the acquisition, analysis, and interpretation of the data; to the drafting of the manuscript; to the critical revision of the manuscript; and to the final approval and agreed to be accountable for all aspects of this work. V.M. and A.M. contributed to the acquisition, analysis, and interpretation of the data; to 
the critical revision of the manuscript; and to the final approval and agreed to be accountable for all aspects of this work. All authors have read and agreed to the published version of the manuscript.

Funding: This research received no external funding.

Institutional Review Board Statement: With respect to the guidelines of the Declaration of Helsinki, this study was conducted according to the Guide for the Care and Use of Laboratory Animals published by the US National Institutes of Health (NIH Publication No. 85-23. revised 1985) and approved by the Biomedical Research Ethics Committee of the Hamadan University of Medical Sciences, Hamadan, Iran (IR.UMSHA.REC.1393.097 on 18 October 2013).

Informed Consent Statement: Not applicable.

Data Availability Statement: All data are reported in the dot blots but are available in tables upon request.

Conflicts of Interest: The authors declare no conflict of interest.

\section{References}

1. Jiang, C.; Li, Z.; Quan, H.; Xiao, L.; Zhao, J.; Jiang, C.; Wang, Y.; Liu, J.; Gou, Y.; An, S.; et al. Osteoimmunology in orthodontic tooth movement. Oral. Dis. 2015, 21, 694-704. [CrossRef]

2. Matsumoto, T.; Iimura, T.; Ogura, K.; Moriyama, K.; Yamaguchi, A. The role of osteocytes in bone resorption during orthodontic tooth movement. J. Dent. Res. 2013, 92, 340-345. [CrossRef]

3. Chaushu, S.; Klein, Y.; Mandelboim, O.; Barenholz, Y.; Fleissig, O. Immune Changes Induced by Orthodontic Forces: A Critical Review. J. Dent. Res. 2021, 220345211016285. [CrossRef]

4. Yamaguchi, M.; Fukasawa, S. Is Inflammation a Friend or Foe for Orthodontic Treatment?: Inflammation in Orthodontically Induced Inflammatory Root Resorption and Accelerating Tooth Movement. Int. J. Mol. Sci. 2021, 22, 2388. [CrossRef]

5. Kirschneck, C.; Kuchler, E.C.; Wahlmann, U.; Proff, P.; Schroder, A. Effects of the highly COX-2-selective analgesic NSAID etoricoxib on the rate of orthodontic tooth movement and cranial growth. Ann. Anat. 2018, 220, 21-28. [CrossRef] [PubMed]

6. Sodagar, A.; Etezadi, T.; Motahhary, P.; Dehpour, A.R.; Vaziri, H.; Khojasteh, A. The effect of celecoxib on orthodontic tooth movement and root resorption in rat. J. Dent. 2013, 10, 303-311.

7. Liu, Y.; Zhang, T.; Zhang, C.; Jin, S.S.; Yang, R.L.; Wang, X.D.; Jiang, N.; Gan, Y.H.; Kou, X.X.; Zhou, Y.H. Aspirin Blocks Orthodontic Relapse via Inhibition of CD4(+) T Lymphocytes. J. Dent. Res. 2017, 96, 586-594. [CrossRef] [PubMed]

8. He, D.; Kou, X.; Yang, R.; Liu, D.; Wang, X.; Luo, Q.; Song, Y.; Liu, F.; Yan, Y.; Gan, Y.; et al. M1-like Macrophage Polarization Promotes Orthodontic Tooth Movement. J. Dent. Res. 2015, 94, 1286-1294. [CrossRef]

9. He, D.; Kou, X.; Luo, Q.; Yang, R.; Liu, D.; Wang, X.; Song, Y.; Cao, H.; Zeng, M.; Gan, Y.; et al. Enhanced M1/M2 macrophage ratio promotes orthodontic root resorption. J. Dent. Res. 2015, 94, 129-139. [CrossRef]

10. Jeon, H.H.; Teixeira, H.; Tsai, A. Mechanistic Insight into Orthodontic Tooth Movement Based on Animal Studies: A Critical Review. J. Clin. Med. 2021, 10, 1733. [CrossRef] [PubMed]

11. Flagg, A.J. Traditional and Current Use of Ginseng. Nurs. Clin. North. Am. 2021, 56, 109-121. [CrossRef] [PubMed]

12. Liu, L.; Xu, F.R.; Wang, Y.Z. Traditional uses, chemical diversity and biological activities of Panax L. (Araliaceae): A review. J. Ethnopharmacol 2020, 263, 112792. [CrossRef] [PubMed]

13. Yang, Y.; Ju, Z.; Yang, Y.; Zhang, Y.; Yang, L.; Wang, Z. Phytochemical analysis of Panax species: A review. J. Ginseng Res. 2021, 45, 1-21. [CrossRef] [PubMed]

14. Zhang, X.; Zhang, B.; Zhang, C.; Sun, G.; Sun, X. Effect of Panax notoginseng Saponins and Major Anti-Obesity Components on Weight Loss. Front. Pharmacol. 2020, 11, 601751. [CrossRef]

15. Xue, Q.; He, N.; Wang, Z.; Fu, X.; Aung, L.H.H.; Liu, Y.; Li, M.; Cho, J.Y.; Yang, Y.; Yu, T. Functional roles and mechanisms of ginsenosides from Panax ginseng in atherosclerosis. J. Ginseng Res. 2021, 45, 22-31. [CrossRef]

16. Wang, S.; Yue, R.; Huang, X.; Li, L.; Xu, C.; Liu, L. Renshen (Panax ginseng) and Huanglian (Rhizoma Coptidis) For T2DM: A protocol of systematic review and meta-analysis of randomized clinical trials. Medicine 2021, 100, e23743. [CrossRef]

17. Kang, Z.; Zhonga, Y.; Wu, T.; Huang, J.; Zhao, H.; Liu, D. Ginsenoside from ginseng: A promising treatment for inflammatory bowel disease. Pharmacol. Rep. 2021, 73, 700-711. [CrossRef]

18. Park, S.K.; Hyun, S.H.; In, G.; Park, C.K.; Kwak, Y.S.; Jang, Y.J.; Kim, B.; Kim, J.H.; Han, C.K. The antioxidant activities of Korean Red Ginseng (Panax ginseng) and ginsenosides: A systemic review through in vivo and clinical trials. J. Ginseng Res. 2021, 45, 41-47. [CrossRef]

19. Hwang, Y.P.; Jeong, H.G. Ginsenoside Rb1 protects against 6-hydroxydopamine-induced oxidative stress by increasing heme oxygenase-1 expression through an estrogen receptor-related PI3K/Akt/Nrf2-dependent pathway in human dopaminergic cells. Toxicol Appl. Pharmacol. 2010, 242, 18-28. [CrossRef]

20. Zeng, X.; Li, J.; Li, Z. Ginsenoside Rd mitigates myocardial ischemia-reperfusion injury via Nrf2/HO-1 signaling pathway. Int. J. Clin. Exp. Med. 2015, 8, 14497-14504. 
21. Katsumata, Y.; Kanzaki, H.; Honda, Y.; Tanaka, T.; Yamaguchi, Y.; Itohiya, K.; Fukaya, S.; Miyamoto, Y.; Narimiya, T.; Wada, S.; et al. Single Local Injection of Epigallocatechin Gallate-Modified Gelatin Attenuates Bone Resorption and Orthodontic Tooth Movement in Mice. Polymers 2018, 10, 1384. [CrossRef]

22. Li, W.; Sun, Y. Nrf2 is required for suppressing osteoclast RANKL-induced differentiation in RAW 264.7 cells via inactivating cannabinoid receptor type 2 with AM630. Regen. Ther. 2020, 14, 191-195. [CrossRef]

23. Florczyk-Soluch, U.; Jozefczuk, E.; Stepniewski, J.; Bukowska-Strakova, K.; Mendel, M.; Viscardi, M.; Nowak, W.N.; Jozkowicz, A.; Dulak, J. Various roles of heme oxygenase-1 in response of bone marrow macrophages to RANKL and in the early stage of osteoclastogenesis. Sci. Rep. 2018, 8, 10797. [CrossRef]

24. Hess, F.G., Jr.; Parent, R.A.; Cox, G.E.; Stevens, K.R.; Becci, P.J. Reproduction study in rats or ginseng extract G115. Food Chem. Toxicol. 1982, 20, 189-192. [CrossRef]

25. Bilia, A.R.; Bergonzi, M.C. The G115 standardized ginseng extract: An example for safety, efficacy, and quality of an herbal medicine. J. Ginseng Res. 2020, 44, 179-193. [CrossRef]

26. Van Kampen, J.; Robertson, H.; Hagg, T.; Drobitch, R. Neuroprotective actions of the ginseng extract G115 in two rodent models of Parkinson's disease. Exp. Neurol. 2003, 184, 521-529. [CrossRef] [PubMed]

27. Terstege, D.J.; MacDonald, D.S.; Tasker, R.A. Standardised ginseng extract G115(R) potentiates the antidepressant-like properties of fluoxetine in the forced swim test. Acta Neuropsychiatr. 2021, 33, 141-147. [CrossRef] [PubMed]

28. Lelovas, P.P.; Xanthos, T.T.; Thoma, S.E.; Lyritis, G.P.; Dontas, I.A. The laboratory rat as an animal model for osteoporosis research. Comp. Med. 2008, 58, 424-430. [PubMed]

29. Ren, Y.; Maltha, J.C.; Van 't Hof, M.A.; Kuijpers-Jagtman, A.M. Age effect on orthodontic tooth movement in rats. J. Dent. Res. 2003, 82, 38-42. [CrossRef]

30. King, G.J.; Fischlschweiger, W. The effect of force magnitude on extractable bone resorptive activity and cemental cratering in orthodontic tooth movement. J. Dent. Res. 1982, 61, 775-779. [CrossRef] [PubMed]

31. Heller, I.J.; Nanda, R. Effect of metabolic alteration of periodontal fibers on orthodontic tooth movement. An experimental study. Am. J. Orthod. 1979, 75, 239-258. [CrossRef]

32. Ahmad Akhoundi, M.S.; Shaygan-Mehr, M.; Keshvad, M.A.; Etemad Moghaddam, S.; Alaeddini, M.; Dehpour, A.; Mirhashemi, A.H. Effect of amitriptyline on orthodontic tooth movement in rats: An experimental study. J. Dent. Res. Dent. Clin. Dent. Prospects 2020, 14, 147-152. [CrossRef] [PubMed]

33. Mirhashemi, A.H.; Akhoundi, M.S.; Ghazanfari, R.; Etemad-Moghadam, S.; Alaeddini, M.; Khorshidian, A.; Dehpour, A.R.; Momeni, N. Assessment of the Role of NO-cGMP Pathway in Orthodontic Tooth Movement Using PDE5 Inhibitors: An Animal Study. J. Dent. 2016, 13, 388-393.

34. Seifi, M.; Asefi, S.; Hatamifard, G.; Lotfi, A. Effect of local injection of Zolena, zoledronic acid made in Iran, on orthodontic tooth movement and root and bone resorption in rats. J. Dent. Res. Dent. Clin. Dent. Prospects 2017, 11, 257-264. [CrossRef] [PubMed]

35. Talebian, R.; Jafari, F.; Dehpour, A.R.; Gruber, R. Effects of lithiumchloride and nitric oxide Inhibitor on orthodontic tooth movement in the rat. Appl. Sci. 2021, 11,3607. [CrossRef]

36. Shirazi, M.; Vaziri, H.; Salari, B.; Motahhari, P.; Etemad-Moghadam, S.; Dehpour, A.R. The effect of caffeine on orthodontic tooth movement in rats. Iran. J. Basic Med. Sci. 2017, 20, 260-264. [CrossRef]

37. Shirazi, M.; Nilforoushan, D.; Alghasi, H.; Dehpour, A.R. The role of nitric oxide in orthodontic tooth movement in rats. Angle Orthod. 2002, 72, 211-215. [CrossRef] [PubMed]

38. Park, E.K.; Shin, Y.W.; Lee, H.U.; Kim, S.S.; Lee, Y.C.; Lee, B.Y.; Kim, D.H. Inhibitory effect of ginsenoside Rb1 and compound K on NO and prostaglandin E2 biosyntheses of RAW264.7 cells induced by lipopolysaccharide. Biol. Pharm. Bull. 2005, 28, 652-656. [CrossRef] [PubMed]

39. Song, Y.B.; An, Y.R.; Kim, S.J.; Park, H.W.; Jung, J.W.; Kyung, J.S.; Hwang, S.Y.; Kim, Y.S. Lipid metabolic effect of Korean red ginseng extract in mice fed on a high-fat diet. J. Sci. Food Agric. 2012, 92, 388-396. [CrossRef]

40. Lee, S.H.; Lee, H.J.; Lee, Y.H.; Lee, B.W.; Cha, B.S.; Kang, E.S.; Ahn, C.W.; Park, J.S.; Kim, H.J.; Lee, E.Y.; et al. Korean red ginseng (Panax ginseng) improves insulin sensitivity in high fat fed Sprague-Dawley rats. Phytother. Res. 2012, 26, 142-147. [CrossRef] [PubMed]

41. Serhan, C.N.; Levy, B.D. Resolvins in inflammation: Emergence of the pro-resolving superfamily of mediators. J. Clin. Invest. 2018, 128, 2657-2669. [CrossRef] [PubMed]

42. Mirfazaelian, A.; Monzavi, A. Use of a feeler gauge to measure the gap between adjacent teeth. J. Prosthet. Dent. 2003, 90, 613. [CrossRef]

43. Siegel, R.K. Ginseng abuse syndrome. Problems with the panacea. JAMA 1979, 241, 1614-1615. [CrossRef] [PubMed]

44. Kim, Y.S.; Woo, J.Y.; Han, C.K.; Chang, I.M. Safety Analysis of Panax Ginseng in Randomized Clinical Trials: A Systematic Review. Medicines 2015, 2, 106-126. [CrossRef] [PubMed] 